\title{
Verbeterde onderrig en opleiding vir studente in die ekonomiese en bestuurswetenskappe deur die instelling van 'n internskap
}

\author{
G J OLIVIER, PF VENTER \& AJE SORGDRAGER \\ Departement Ondernemingsbestuur, Universiteit Vista
}

Die huidige opleiding van bestuurders is steeds tot ' $n$ groot mate geskoei op die tradisionele onderrigmodel: teoretoiese opleiding in die klaskamer met behulp van lesings en transpararante. Volgens ' $n$ opname onder afgestudeerde studente, bevredig hierdie onderrigmodel nie die behoeftes van die sakelui nie. Die instelling van ' $n$ internskap word voorgestel om die opleiding meer praktykgerig te maak.

\section{INLEIDING}

Ter inleiding word die omstandighede omskryf waaronder onderrig en opleiding van bestuurders plaasvind met veral 'n verwysing na die probleme wat ervaar word en die redes wat gelei het tot verskeie ondersoeke na die onderrig en opleiding van bestuurders in Suid-Afrika.

\section{Agtergrondinligting}

In die laaste dekade van die twintigste eeu is bykans elke aspek van die mensdom se voortbestaan aan die een of ander proses van verandering blootgestel. Die veranderingstendens manifesteer in verskillende vorme. Begrippe en prosesse soos demokratisering, hervorming, normalisering, rasionalisering en transformasie het almal een gemeenskaplike element, naamlik dié van verandering. Tewens, in hierdie tye van onsekerheid is ten minste een konstante faktor deurgaans aanwesig en sonder vrees vir teënspraak kan gesê word dat dit net verandering kan wees!

Ook die ekonomiese en bestuurswetenskappe, en bestuur in die besonder, het nie die proses van verandering vrygespring nie. Om hierdie rede moet die onderrig en opleiding van toekomstige bestuurders ook aandag aan aanpassings of verandering gee.

Die veranderde vereistes vir die onderrig en opleiding van toekomstige bestuurders, die aanpassing by veranderde omstandighede of die gebrek aan aanpassing, het wêreldwyd tot verskeie ondersoeke en verslae gelei. Gedurende 1989 alleen het Porter en McKibbin in die VSA 'n verslag uitgebring, Rogers het verslag gelewer oor bestuurskole in Brittanje en Europa, terwyl die Wêreldbank ook 'n verslag oor bestuursopleiding die lig laat sien het.

In die RSA het die destydse Nasionale Mannekragkommissie en die Nasionale Opleidingsraad in 1986 gesamentlik 'n verslag gepubliseer oor die opleiding en ontwikkeling van bestuurders. Die ondersoek het hoofsaaklik gekonsentreer op voorgraadse verskaffers en gebruikers van bestuursopleiding. Gedurende 1987 het Slabbert verslag gelewer oor 'n aantal MBA-gegradueerdes se bestuursopleiding. Meer onlangs, in 1997, het Jonker en Otto onderskeidelik in MBA-skripsies besonder skerp kritiek teen die nagraadse kwalifikasie gelewer.

\section{Probleemstelling}

In 1990 het die Nasionale Opleidingsraad 'n verslag uitgebring wat spesifiek verwys na die veranderende rol van bestuur oor die volgende dekade.

Dit is veral die gebrek aan aanpassing by veranderende omstandighede vir die onderrig en opleiding van toekomstige bestuurders wat in die verslag van die Nasionale Opleidingsraad aangespreek word. In die 
verslag is onder andere vermeld:

- Bestuursopleiding aan Suid-Afrikaanse tersiêre inrigtings is ontoereikend om in die behoeftes van toekomsbestuur te voldoen (Nasionale Opleidingsraad 1990:109).

- Universiteite, bestuurskole en technikons moet bestaande bestuursopleidingsprogramme dringend herevalueer (Nasionale Opleidingsraad 1990:115).

Alhoewel universiteite en technikons deurlopend aandag skenk aan die aanpassing van leerplanne, kon die vraag tog aan die einde van die negentigerjare gevra word tot watter mate aandag aan die kritiek van bogemelde verslag gegee is. Dikwels word 'n bespreking "oor" studente se werkprestasie gevoer maar selde word direk "met" afgestudeerde studente geskakel. Om die leemte aan te spreek is 'n opvolgevalueringsondersoek gedoen na die onderrig-, opleidings- en werkervaring van afgestudeerde universiteit- en technikonstudente in die ekonomiese en bestuurswetenskappe. Enkele resultate van hierdie opvolgondersoek en voortvloeiende aanbevelings word in die artikel bespreek.

\section{Doel en metode van die ondersoek}

Die doel van die ondersoek is in die woorde van Porter \& McKibbin (1989:9) "... to find out as much as possible what was really happening out there" ten einde tekortkominge in die onderrig- en opleidingstelsel te identifiseer met die oog daarop om dit uit te skakel.

Vir die insameling van inligting is 'n posvraelys aan onderskeidelik 2000 afgestudeerde universiteitstudente en 2000 afgestudeerde technikonstudente gestuur. 'n Respons van 802 bruikbare vraelyste is ontvang. Verslag word in hierdie artikel oor die resultate gelewer. Behalwe vir die verkryging van besonderhede oor die biografiese agtergrond van respondente, hul kwalifikasies en beroepsinligting, is hoofsaaklik van 'n Likertskaal gebruik gemaak waarin persepsies van respondente op 'n skaal van 1 tot 7 getoets is. Die vraelys het ' $n$ breë veld gedek met betrekking tot die evaluering van huidige en toekomstige onderrig en opleiding. Die toepaslike resultate word vervolgens bespreek.

\section{RESULTATE}

Ter wille van duidelikheid word die terme evaluering van onderrighulpmiddele, die aanbieding van teorie in die klassituasie en aspekte van toekomstige onderrig en opleiding uiteengesit.

\section{Evaluering van onderrighulpmiddele}

Die respondente is versoek om aan te dui in watter mate daar tydens hul studie van die volgende onderrighulpmiddele gebruik gemaak is. ' $n$ Likertskaal is gebruik met $1=$ Nooit en $7=$ Altyd. Die response wat verkry is, word in Tabel 1 aangetton.

\section{Tabel 1 Gebruik van onderrighulpmiddele}

Onderrigmetode/hulpmiddel

Formele lesings

Besprekingsklasse en gevallestudies

Transparante

Films en video-opnames

Gesimuleerde werksituasies

Praktykkamers en demonstrasies

Rekenaars en verwante hulpmiddele

$\begin{array}{rr}\text { Nooit } & \text { Altyd } \\ 11,2 \% & 72,2 \% \\ 16,0 \% & 27,5 \% \\ 22,9 \% & 28,3 \% \\ 51,6 \% & 6,6 \% \\ 50,9 \% & 7,2 \% \\ 56,2 \% & 5,2 \% \\ 71,7 \% & 4,8 \%\end{array}$


Gasdosente en/of sprekers

Fabrieks- en ondernemingsbesoeke

Veldwerkopnames

$\begin{array}{ll}56,8 \% & 6,5 \% \\ 73,1 \% & 2,9 \% \\ 72,1 \% & 3,3 \%\end{array}$

Die lesingmetode, besprekingsklasse en transparante word hoofsaaklik gebruik terwyl ander hulpmiddele in 'n aansienlik mindere mate aangewend word. Dit blyk dat die oorblywende onderrigmetodes en hulpmiddele met veel groter vrug aangewend kan word.

\section{Aanbieding van die teorie in die klassituasie}

Die aanbieding van die teoretiese aspekte van verskillende vakke tydens die afgestudeerde student se studietermyn, het die response gelewer soos in tabel 2 aangetoon.

Tabel 2 Aanbieding van die teorie

\author{
Teoretiese aspekte beklemtoon \\ Toepassing van teorie in die klas beklemtoon \\ Toepassing van teorie by werksituasie
}

$\begin{array}{rr}\text { Nooit } & \text { Altyd } \\ 1,4 \% & 64,3 \% \\ 8,7 \% & 35,4 \% \\ 31,7 \% & 16,4 \%\end{array}$

Volgens die inligting word die vakinhoude hoofsaaklik teoreties aangebied met weinig geleenthede vir toepassing om insig en vaardighede te ontwikkel.

\section{Aspekte van toekomstige onderrig en opleiding}

Die respondente se mening oor toekomstige onderrig en opleiding het resultate gelewer soos in Tabel 3 aangetoon.

Tabel 3 Toekomstige onderrig en opleiding

\section{Aspekte van onderrig en opleiding}

Stem nie saam \% Stem saam

1 Beklemtoning van teoretiese onderrig

$14,2 \quad 18,8$

2 Beklemtoning van praktykgerigte onderrig

$0,1 \quad 84,3$

3 Beklemtoning van tegnieke

4 Beklemtoning van tegnologie

1,0

72,1

5 Beklemtoning van vaardighede

75,3

6 Periode van internskap

7 'n Mentor vir toekomstige bestuurders

$0,1 \quad 77,7$

8 Ontwikkeling van skeppende denke

Uit die tabel kan die volgende oor die toekomstige onderrig en opleiding van bestuurders afgelei word:

- Die respondente se siening oor die beklemtoning van teoretiese onderrig was ongeveer 14,2 persent daarteen en 18,8 persent wat daarmee saamstem. Die afleiding kan gemaak word dat teoretiese onderrig beklemtoon kan word maar dat daar 'n aansienlike persentasie is wat nie met die siening saamstem nie. 
- Die teendeel van teoretiese onderrig, te wete praktykgerigte onderrig, vind baie meer ondersteuning. Die respondente het met 84,3 persent saamgestem dat praktykgerigte onderrig beklemtoon moet word met slegs 0,1 persent van die respondente wat nie saamstem nie.

- Wat die beklemtoning van tegnieke, tegnologie en vaardighede betref, lyk die situasie soos volg:

$$
\begin{aligned}
& \text { tegnieke } \\
& \text { tegnologie } \\
& \text { vaardighede }
\end{aligned}
$$

72,1 persent stem saam

75,3 persent stem saam

77,7 persent stem saam

Diegene wat nie saamstem nie, vorm 'n onbenullige klein persentasie.

- 'n Periode van internskap (52,7 persent) vind minder byval as die voorgaande stellings. Wanneer die response 5 tot 7 saamgevoeg word, is daar 74,5 persent wat saamstem terwyl 11,5 persent nie saamstem nie.

- Die ontwikkeling van skeppende denke het ondersteuning van 74,6 persent uitgelok terwyl slegs 1,0 persent respondente nie daarmee saamstem nie.

Die resultate van die ondersoek kan in die volgende stelling saamgevat word:

Vir die onderrig en opleiding van toekomstige bestuurders moet praktykgerigte onderrig, tegnieke, tegnologie en vaardighede beklemtoon word. Hierbenewens vind 'n periode van internskap, 'n mentor tydens die internskap en die ontwikkeling van skeppende denke ook byval by die meerderheid respondente.

Die vraag wat onvermydelik na vore kom is hoe om die bevindinge van die ondersoek in die praktyk uit te voer. Dit word vervolgens in ' $n$ reeks aanbevelings uiteengesit.

\section{AANBEVELINGS VIR TERSIÊRE OPVOEDKUNDIGE INSTELLINGS}

Die volgende aanbevelings geld vir tersiêre opvoedkundige instellings met kursusse in die ekonomiese en bestuursgerigte studierigtings.

\section{Toepassing van kennis en vaardighede}

'n Vorm van toepassing van kennis en vaardighede in die praktyk moet bevorder word deur van voltydse voorgraadse studente te verwag om diens te lewer wat ooreenstem met byvoorbeeld die:

- hospitaaljaar of verpligte gemeenskapsdiens by mediese studente;

- internskap by professionele sielkundiges;

- klerkskap by prokureurs en rekenmeesters;

- proefonderwys by onderwysstudente.

Vir die opleiding van bestuurstudente word voorgestel dat die praktykopleiding die vorm van ' $\mathrm{n}$ verpligte internskap aanneem.

\section{Stelsel van ' $\mathrm{n}$ internskap}

Daar kan na die stelsel as 'n internskap of akademiese plig verwys word en die verwerwing van 'n kwalifikasie moet onderhewig aan die suksesvolle voltooiing van die internskap wees.

Alhoewel die voorstel in Suid-Afrika as ingrypend beskou kan word, het die praktyk van internskappe reeds 
inslag in Europa gevind. Studente van die "Hautes Ecole Commerciale" (HEC), gestig deur die Franse Kamers van Handel, word verwag om deel te neem aan verskeie "on-site job training experiences, including six weeks on the shop floor as 'n blue-collar worker in their first year and three months in a fulltime professional position during their final year." Die HEC en ander prestige instansies maak ook voorsiening vir oorsese internskappe wat ' $n$ ses tot agt weke werkbesoek aan ' $n$ buitelandse onderneming insluit gedurende die reses wat die finale jaar voorafgaan. Alhoewel die praktyk van internskap veel meer inslag in Europa as in die VSA gevind het, het die Universiteit van Kalifornië 'n nie-winsbejag maatskappy gevorm wat gemoeid is met die aanvaarding en uitvoering van veldwerk. Voorstelle is al gemaak dat voltydse MBA-kursusse uitgefaseer word ten gunste van 'n bestuurdersvakleerlingskap (Paul, Ickis \& Levitsky 1989:46-47).

\section{- $\quad$ Die wese van die internskap}

Die wese van die internskap behels dat van ' $n$ student verwag word om blootstelling te kry in die praktyk deur die toepassing van teoretiese kennis by ' $n$ goedgekeurde instelling. Die ideale situasie is dat ' $n$ student blootgestel word aan werk wat ooreenstem met die studierigting van die student. 


\section{- Implementering van 'n internskap}

Die suksesvolle implementering van 'n internskap kan verskillende vorme aanneem wat kan wissel na gelang van die aard van die opvoedkundige instelling, byvoorbeeld universiteit of technikon. Alhoewel daar nie eng voorskrifte is ten opsigte van wanneer die internskap moet plaasvind nie, sou die mees gewenste tyd wees tydens die studentevakansie in November tot einde Januarie, of selfs gedurende Junie-Julie reses. Werk op ' $n$ deeltydse grondslag gedurende die week of naweke kan ook aanvaarbaar wees.

\section{- $\quad$ Aanstelling van mentors}

Dit word voorgestel dat afgetrede dosente, sakelui of handelsvakonderwysers as mentors aangestel word om die studente wat besig is met ' $n$ internskap by te staan, hul vordering te moniteer en periodiek aan die opvoedkundige instelling en dosente betrokke by die instelling te rapporteer.

\section{- Vereistes vir 'n internskap}

Daar moet verseker word dat die vereistes vir 'n internskap nagekom word.

- Die student moet 'n bevredigende verslag indien oor die relevansie van die akademiese inhoud wat bestudeer is en die werk wat tydens die internskap verrig is. Twee kopieë moet voorsien word: een aan die werkgewer gerig en die ander aan die opvoedkundige instelling se departement waarby die student betrokke is. Die inligting kan onder meer aangewend word om leerplan-inhoud met die praktyk te vergelyk en waar nodig aanpassings te maak.

- Studente se verslae, tesame met die mentor se indrukspunt, kan as 'n inset gebruik word vir 'n deurlopende evalueringspunt.

- Die student moet bewys lewer van die aantal dae of ure diens wat verrig is. Die werkgewer behoort die dienstermyn te bevestig.

- Die student behoort ook bewys te lewer van goeie gedrag en bevredigende diens by die werkgewer.

\section{- Administratiewe afdelings}

Afdelings of departemente moet by die opvoedkundige instellings gevorm word vir die:

- Daarstelling van 'n rekorderingstelsel om die vordering en nakoming van die vereistes van 'n internskap deur bevredigende werkverrigting en voltooiing van verslae op datum te hou.

- Administrasie van die internskap ten opsigte van registrasie van werkgewer, tydperk van diens verrig en verslae ingedien. Die verkryging van werkgeleenthede bly die verantwoordelikheid van die student.

- Onderhandelinge met belastingowerhede

Onderhandelinge met belastingowerhede behoort aangegaan te word waarvolgens 'n belastingpligtige sake-onderneming die uitgawes verbonde aan studente vergoeding kan aftrek van winste of 'n verminderde opleidingsheffing betaal. 


\section{- Praktykgerigte vakinhoud}

Vanweë die aandrang van afgestudeerde universiteit- en technikonstudente en die oproepe van die georganiseerde handel en nywerheid asook van sakelui, moet aandag geskenk word aan die leerplanne, leerstof en die benadering van dosente om die vakinhoud meer praktykgerig te maak. Die fundamentele wetenskaplike teorieë en beginsels behoort steeds genoegsame aandag te kry waar aspekte soos die tegnologie, tegniek en vaardigheid beklemtoon word. Die toepassing daarvan soos dit in die praktyk te vinde is, moet in die klassituasie beklemtoon word sodat studente beter voorbereid is met die oog op 'n beroepsloopbaan.

\section{- $\quad$ Skakeling met die georganiseerde handel, nywerheid en die sakelewe}

Noue skakeling met die georganiseerde handel, nywerheid en die sakelewe in die breë deur dosente behoort op 'n deurlopende grondslag uitgevoer te word.

- Werkopdragte, take en navorsingsprojekte

Werkopdragte, take en navorsingsprojekte moet benewens die wetenskaplike teorie ook verband hou met die praktyk.

\section{- Blootstelling aan die praktyk}

Studente moet blootstelling aan die praktyk kry gedurende resestydperke deur een of meer van die volgende praktykgerigte aktiwiteite uit te voer ten einde die internskap as vereiste vir die verwerwing van 'n kwalifikasie na te kom. Dit kan bereik word deur:

- In diens te wees by 'n sake-onderneming of werkgewer wat belastingpligtig is en teen ' $n$ vergoeding werk verrig wat relevant tot vakinhoude is.

- As navorsingsassistente by 'n navorsingsinstansie (waaronder universiteite of technikons) behulpsaam te wees met veldwerk of opnames teen 'n billike vergoeding.

- As ' $n$ junior dosent en of studente-assistent of tutor by ' $n$ universiteit of technikon behulpsaam te wees met onderrig vir besprekingsklasse, nasienwerk en administrasie.

\section{Die tydsduur van die internskap}

Die tydsduur van die internskap oor die tydperk van drie studiejare behoort gelykstaande te wees aan 40 werksdae of 320 werkure vir ' $n$ universiteitstudent. Vanweë die praktykgerigtheid van technikonkursusse behoort die tydsduur van internskap gelykstaande te wees aan 60 werksdae of 480 werkure.

\section{SLOTOPMERKING}

By terugskouing van die opvolgevalueringsondersoek na die onderrig-, opleidings- en werkervaring van afgestudeerde studente in die ekonomiese en bestuurswetenskappe het ' $n$ enkele feit soos ' $n$ goue draad deur bykans al die respondente se antwoorde na vore gekom. Dit was dat leerplanne, vakinhoude, onderrig- en opleidingsmetodes en dosente die studente meer en beter moet voorberei vir die werksituasie soos dit in die praktyk gevinde word.

Universiteite en technikons gaan toenemend met die eindprodukte van uitkomsgebaseerde onderwys te doen kry. Hiervolgens gaan sowel studente as werkgewers by universiteite en technikons aandring om verbeterde onderrig en opleiding aan te bied. 
Die instelling van ' $n$ intern- en mentorskap mag ' $n$ bydrae tot verbeterde onderrig en opleiding lewer en daarmee saam ook ten dele ' $n$ antwoord bied op die deurlopende kritiek wat op universiteite en technikons gelewer word.

\section{BRONNELYS}

JONKER WD. 1997. A follow up study on the educational experience of MBA graduates. . Pretoria. Universiteit van Pretoria. [MBA short dissertation.]

KATZ M. 1995. Cooperative education : advantages all around. People Dynamics, 13(2):37, February.

MAKWETLA A. 1998. Mentoring overcomes the hurdles. Productivity South Africa, 24(6):29-30. November/December.

NASIONALE MANNEKRAGKOMMISSIE EN NASIONALE OPLEIDINGSRAAD. 1986. Die opleiding en ontwikkeling van bestuurders in die RSA, 1983/84 - 'n feite-ondersoek. Pretoria : Staatsdrukker (RP92/1986).

NASIONALE OPLEIDINGSRAAD. 1990. Die veranderende rol van bestuur oor die volgende dekade - ' $n$ kritiese beskouing. Pretoria: Departement van Mannekrag.

OLIVIER GJ. 1997. Die onderrig en opleiding van laevlakbestuurders. Pretoria : Universiteit Vista. [PhD-proefskrif.]

OTTO PP. 1997. A comparison of the perceptions regarding MBA students of different steakholders. Pretoria: Universiteit van Pretoria. [MBA short dissertation.]

PAUL S, ICKIS JC \& LEVITSKY J. 1989. Educating managers for Business and Government: a review of international experience. World Bank Discussion Papers, 54. Washington DC : World Bank.

PORTER LW \& MCKIBBIN LE. 1988. Management education and development: drift or thrust into the 21st century? New York : McGraw-Hill.

ROGERS J. 1988. MBA: the best business tool? A guide to British and European business schools. London : Economist Publications.

SLABBERT I. 1987. An evaluation of the management training and the career anchors of a group of MBA/MBL graduates. Pretoria : HSRC (Report MM 116). 